\title{
Protective Effect of Taurine against Ammonia-Induced Gastric Mucosal Lesions in Rats
}

\author{
Motonobu MURAKAMI, Jung Keun YOO, Sanae TERAMURA, \\ Ko YAMAMOTO, Hiroshi SAITA, Toru KITA and Takeo MIYAKE ${ }^{1}$ \\ Department of Geriatric Medicine. Faculty of Medicine, \\ Kyoto University, Kyoto 606, Japan \\ ${ }^{1}$ National Kyoto Hospital. Kyoto 612, Japan
}

Accepted September 22, 1989

\begin{abstract}
We examined the role of gastric ammonia in the development of gastric lesions in rats. Exposure of the gastric mucosa to ammonia $(30 \mathrm{mM})$ produced microscopic injury, but no macroscopic lesion was observed. However, exposure of the stomach to ammonia in rats subjected to ischemia resulted in macroscopic gastric lesions. The macroscopic lesions were markedly inhibited by pretreatment with taurine, a scavenger of hypochlorous acid $(\mathrm{HOCl})$ and monochloramine $\left(\mathrm{NH}_{2} \mathrm{Cl}\right)$. These results indicate that ammonia is deleterious to gastric mucosa, and monochloramine may be involved in the pathogenesis of ammonia-induced mucosal lesions.
\end{abstract}

Recent evidence suggests that reactive oxygen metabolites $\left(\mathrm{O}_{2}{ }^{-}, \mathrm{H}_{2} \mathrm{O}_{2}\right)$ are mediators of the tissue injury associated with ischemia $(1,2)$. In the ischemic stomach of the rat, xanthine oxidase and neutrophilic myeloperoxidase (MPO) are activated (3). Superoxide anion $\left(\mathrm{O}_{2}{ }^{-}\right)$is reduced spontaneously or by superoxide dismutase to $\mathrm{H}_{2} \mathrm{O}_{2} \cdot \mathrm{H}_{2} \mathrm{O}_{2}$ oxidizes $\mathrm{Cl}^{-}$in the presence of MPO to yield hypochlorous acid $(\mathrm{HOCl})$, which reacts with $\mathrm{NH}_{3}$ to yield monochloramine $\left(\mathrm{NH}_{2} \mathrm{Cl}\right)$ (4. 5).

Recent evidence has demonstrated that the stomach with Campylobacter pylori (CP) infection contains a high concentration of toxic ammonia and that $C P$ infection is associated with active chronic gastritis (6. 7). However, the pathophysiological role of elevated ammonia in the stomach is unknown. We recently demonstrated that exposure of the stomach of rats to ammonia or urea with urease resulted in gastric mucosal lesions (8-10). High concentrations of ammonia (0.5-1.0\%) caused macroscopic lesions, but low concentrations $(0.025-0.1 \%)$ produced only microscopic injury (7). We hypothesized that ammonia damages the gastric mucosa via conversion to $\mathrm{NH}_{2} \mathrm{Cl}$, a potent toxic oxidant. In this study, we have examined whether or not taurine $\left(\mathrm{H}_{2} \mathrm{NCH}_{2}-\right.$ $\mathrm{CH}_{2} \mathrm{SO}_{3} \mathrm{H}$ ), a scavenger of $\mathrm{HOCl}$ and $\mathrm{NH}_{2} \mathrm{Cl}$. protects gastric mucosa against the deleterious effect of ammonia.

Male Sprague Dawley rats $(220-250 \mathrm{~g})$ were deprived of food, but allowed free access to water for $24 \mathrm{hr}$ prior to the experiments. Rats were anesthetized with urethane, ano an ex vivo gastric chamber was prepared (11). The chamber was filled with $2 \mathrm{ml}$ of saline, and transmucosal potential difference (PD) was continuously recorded as an index of mucosal integrity. Rats were subjected to ischemia (reduction of blood pressure to 30 $\mathrm{mmHg}$ by withdrawal of blood from femoral vein) with or without exposure of the gastric mucosa to $30 \mathrm{mM}$ ammonia (ca. $0.05 \%$ ). Ammonia was diluted in saline. Pretreatment with taurine was given $30 \mathrm{~min}$ before administration of ammonia. The animals were killed after $1 \mathrm{hr}$ exposure to ammonia, and the stomach was examined for macroscopic lesions under a dissecting microscope. The area of each lesion was measured, and the summation of areas was used as the total lesion area $\left(\mathrm{mm}^{2}\right)$. Statistical analysis was performed using Student's $t$-test. 


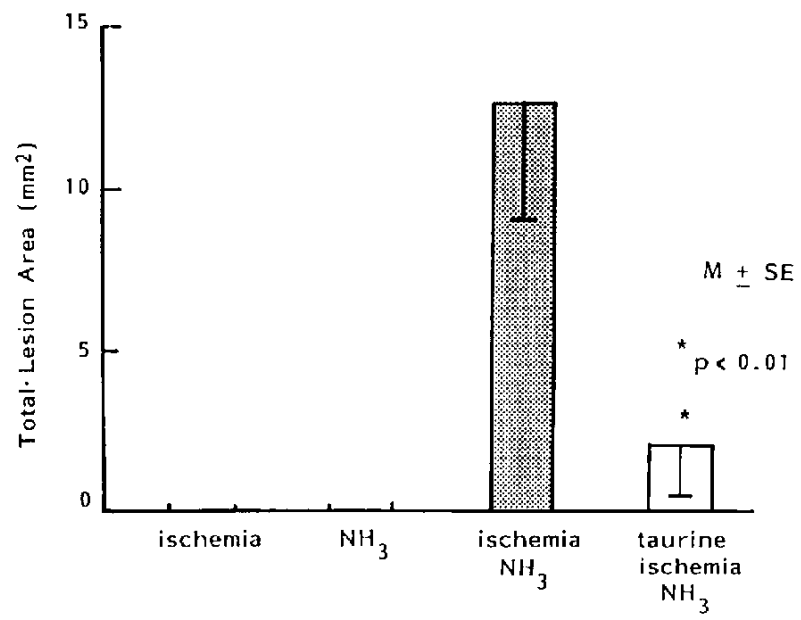

Fig. 1. Effect of ischemia, ischemia plus $30 \mathrm{mM} \mathrm{NH}_{3}$, and $30 \mathrm{mM} \mathrm{NH}_{3}$ on gastric mucosa. Ischemia or $\mathrm{NH}_{3}$ alone did not produce macroscopic lesions. Exposure of the gastric mucosa to ammonia in rats subjected to ischemia produced macroscopic hemorhagic erosions. Pretreatment with taurine significantly inhibited ammonia plus ischemia induced lesions.

Withdrawal of blood $(3-3.5 \mathrm{ml})$ from the femoral vein resulted in a reduction of systemic blood pressure to about $30 \mathrm{mmHg}$. In rats subjected to ischemia alone, transmucosal PD level was decreased for only a short period, and no macroscopic lesion was observed. In contrast. when rats were subjected to ischemia before the gastric mucosa was exposed to $30 \mathrm{mM}$ ammonia, significant macroscopic gastric lesions and a marked decrease in transmucosal PD were observed after exposure to ammonia. Pretreatment with taurine (instillation of $2 \mathrm{ml}$ of $250 \mathrm{mM}$ taurine into the gastric chamber for $30 \mathrm{~min}$ ) significantly inhibited both the development of ammonia-induced macroscopic lesions and the decrease in transmucosal PD. Exposure of the gastric mucosa to $30 \mathrm{mM}$ ammonia without ischemia resulted in a slight decrease of transmucosal PD and histological gastric mucosal injury, but no macroscopic lesion was observed (Figs. 1 and 2).

Recent evidence has indicated that the ammonia in the stomach is produced from hydrolysis of urea by the urease of CP (6). Our study demonstrated that $30 \mathrm{mM}$ ammonia induced macroscopic mucosal lesions in the pathological state of ischemia. In the ischemic state, superoxide anion. $\mathrm{H}_{2} \mathrm{O}_{2}$, and $\mathrm{HOCl}$ increase due to activation of neutrophilic oxidase or conversion of xanthine

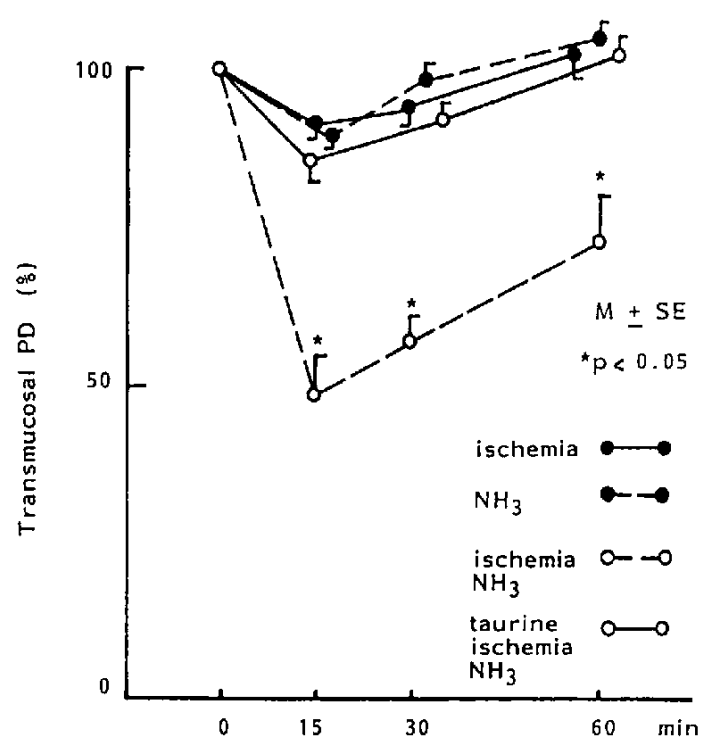

Fig. 2. Effect of ischemia and ischemia plus $30 \mathrm{mM}$ $\mathrm{NH}^{3}$ on gastric transmucosal potential difference (PD). Normal stomach generated a stable PD of $-35 \sim-40 \mathrm{mV}$ (mucosa negative) under the present condition before instillation of ammonia and/or ischemia. The change in PD was calculated by expressing the PD as a percentage of PD before exposure of the stomach to ammonia and/or ischemia. Ischemia plus ammonia produced a marked decrease in PD (O-..-- O). Pretreatment with taurine inhibited the fall of $P D$ in rats subjected to ammonia plus ischemia $(\bigcirc-O)$. 
dehydrogenase to oxidase. $\mathrm{HOCl}$ is unstable and reacts with endogenous nitrogen compounds such as ammonia and taurine to vield derivatives containing a nitrogenchlorine $(\mathrm{N}-\mathrm{Cl})$ bond $(5,12)$. The reaction of $\mathrm{HOCl}$ with $\mathrm{NH}_{3}$ yields $\mathrm{NH}_{2} \mathrm{Cl}$. $\mathrm{NH}_{2} \mathrm{Cl}$ is a powerful oxidizing agent that reacts rapidly with target cell components. In contrast, the reaction of $\mathrm{HOCl}$ with taurine yields taurinechloramine (TauNHCl). TauN $\mathrm{HCl}$ is hydrophilic and has little toxicity as an oxidant (12). Taurine acts as a scavenger of $\mathrm{HOCl}$ and $\mathrm{NH}_{2} \mathrm{Cl}$, protecting cells against oxidative attack of $\mathrm{NH}_{2} \mathrm{Cl}$ by competing with $\mathrm{NH}_{3}$ for reaction with $\mathrm{HOCl}$.

$$
\mathrm{NH}_{3}+\mathrm{HOCl} \rightarrow \mathrm{NH}_{2} \mathrm{Cl}+\mathrm{H}_{2} \mathrm{O}
$$

Taurine $+\mathrm{HOCl} \rightarrow$ TauN HCl$+\mathrm{H}_{2} \mathrm{O}$

Taurine $+\mathrm{NH}_{2} \mathrm{Cl} \rightarrow \mathrm{TauNHCl}+\mathrm{NH}_{3}$

Thus the protective effect of taurine against the deleterious effect of ammonia plus ischemia suggests that ammonia damages gastric mucosa by its conversion to $\mathrm{NH}_{2} \mathrm{Cl}$.

\section{References}

1 Ito, M. and Guth, P.H.: Role of oxygen-derived free radicals in hemorrhagic shock-induced gastric lesions in the rat. Gastroenterology 88 , 1162-1167 (1985)

2 Weiss, S.J.: Oxygen, ischemia and inflammation. Acta Physiol. Scand. Supp. 548, 9-37 (1986)

3 Grisham, M.B. and Granger, D.N.: Neutrophilmediated mucosal injury: Role of reactive oxygen metabolites. Dig. Dis. Sci. 33, 6s-15s (1988)

4 Harrison, J.E. and Schults, J.: Studies on the chlorinating activity of myeloperoxidase. J.
Biol. Chem. 251, 1371-1374 (1976)

5 Weiss, S.J., Klein, R., Slivka, A. and Wei, M.: Chlorination of taurine by human neutrophils: Evidence for hypochlorous acid generation. J. Clin. Invest. 70, 598-607 (1982)

6 Marshall, B.J. and Jangton, S.R.: Urea hydrolysis of patients with Campylobacter pyloridis infection. Lancet i, 965-966 (1986)

7 Murakami, M., Yoo, J.K., Mizuno, M., Saita, H., Inada, M. and Miyake, T.: Role of gastric ammonia, urea and urease in gastric mucosal lesions in azotemia. Gastroenterology 92, 1545 (Abstract) (1987)

8 Murakami, M., Yoo, J.K., Inada, M. and Miyake, T.: Effect of ammonia on the gastric mucosa in rats: Pathophysiological importance of urease in gastric ulcer disease. Japan. J. Pharmacol. 47. 330-332 (1988)

9 Murakami, M., Mizuno, M., Ashida, Y., Saita, H., Hozu, S., Inoue, R., Inada, M. and Miyake, T.: Effect of prostaglandin on $\mathrm{NH}_{3}$-induced gastric mucosal lesions. Gastroenterology 90, 1560 (Abstract) (1986)

10 Murakami, M., Yoo, J.K., Mizuno, M., Saita ${ }_{r}$ H., Inda, M. and Miyake, T.: Effect of ammonia, urea, and urease on the rat gastric mucosa. Gastroenterology 92, 1544 (Abstract) (1987)

11 Mersereau, W.A. and Hinchey, E.J.: Effect of gastric acidity on gastric ulceration induced by hemorrhage in the rat, utilizing a gastric chamber technique. Gastroenterology 64, 1130-1135 (1973)

12 Weiss, S.J., Lampert, M.B. and Test, S.T.: Longlived oxidants generated by human neutrophils: Characterization and bioactivity. Science 222 , 625-628 (1983) 